\title{
INSIGHTS INTO CORONA/CORONAVIRUS DISEASE 2019 PANDEMIC - OPINION VERSUS EVIDENCE
}

\author{
PARTHASARATHY ${ }^{1 *}$, MONISHA SUNDARARAJAN ${ }^{2}$, MANIMARAN A ${ }^{3}$
}

${ }^{1}$ Department of Anaesthesiology, Mahatma Gandhi Medical College and Research Institute, Sri Balaji Vidyapeeth, Bahour, Puducherry, India. ${ }^{2}$ Department of Anaesthesiology, MGM Health Care, Chennai, Tamil Nadu, India. ${ }^{3}$ Department of Internal Medicine, Thanjavur Medical College, Thanjavur, Tamil Nadu, India. Email: painfreepartha@gmail.com

Received: 09 April 2021, Revised and Accepted: 28 May 2021

\section{ABSTRACT}

The pandemic of coronavirus disease 2019 (COVID-19) struck the globe in December 2019, killing lakhs of people and it is continuing in many countries to create havoc. There are lakhs of publications creating evidence about the management of the disease. After seeing thousands of cases, we formed opinions in each field of management and these findings may look more logical. We accept that our opinions differ subtly from the evidence. Regarding the transmission of the disease, it is spread from person to person through inhaled aerosols. If this is going to be $100 \%$ true, then the need for personal protective equipment covering the legs seems illogical. Povidone-iodine is antiviral and spreading the same as an ointment inside the nose must be effective to decrease viral load. The other antivirals with questionable efficiency like remdesivir are being used frequently, especially in the pulmonary phase. There are no clear-cut guidelines for primary contacts. Any protective drug intake could have decreased the transmission. It's a simple logic that the act of sneezing will decrease the viral load. The practice of inhaling turmeric smoke to induce sneezing in the outdoor could have decreased the viral load. We opine that a lymphopenia of $<15 \%$ can predict a worse outcome in the next 2 days. A computerized computed tomography scan of the chest is to be taken 7 days after the onset of symptoms as the disease usually enters the pulmonary phase only then. The date of onset of symptoms rather than the positive testing date should be considered for timeline management of the case. The undue tachycardia in the $1^{\text {st }}$ week and desaturation below $92 \%$ in the $2^{\text {nd }}$ week are the warning signs. The steroids are to be usually prescribed after the 5-6 days. The roles of psychiatric counseling and nutrition were largely underplayed.

Keywords: Coronavirus disease 2019, Management, Opinion, Drugs, Evidence, Iodine, Nutrition, Health, Mental.

(c) 2021 The Authors. Published by Innovare Academic Sciences Pvt Ltd. This is an open access article under the CC BY license (http://creativecommons.org/ licenses/by/4.0/) DOI: http://dx.doi.org/10.22159/ajpcr.2021v14i7.41754. Journal homepage: https://innovareacademics.in/journals/index.php/ajpcr

\section{INTRODUCTION}

The severe acute respiratory syndrome (SARS) coronavirus 2/coronavirus disease 2019 (COVID-19) has rapidly spread from its origin in Wuhan City of China to the rest of the world. Globally, it has infected around 12 crore people with 26 lakh deaths and the toll is increasing day by day even now in almost all the countries [1]. The major route of getting infected is through the large droplets from patients and entering the nose of the fresh patient. The virus replicates in the nasopharynx, spreads in three possible ways from there. The first one is the lungs, where it sets up a cytokine storm to cause life-threatening lung damage. The second one is the gastroenteric system where it can cause diarrhea and dehydration. The third path is that the virus may go up to cause inflammatory damage to the olfactory nerves to produce a loss of smell [2]. The loss of taste is the aftermath of loss of smell rather than any separate taste loss. The fever, cough, and sore throat are some of the clinical features, but exhaustion and fatigue dominate. Once the virus sets in, it initiates a cytokine storm which causes damage to the lungs. This damage, according to the extent of involvement, produces hypoxemia progressing to type 1 respiratory failure. The reverse transcriptase polymerized chain reaction (RT-PCR) to identify the virus in the nasopharyngeal swab is still the confirmatory test. There are hints about its severity from the rise of acute-phase reactants and D-Dimer values, but the computed tomography (CT) chest changes separated the ill from the normal. Recently, lung opacities have been termed as micro emboli. Hence, antiviral drugs along with heparin and steroids have been used for the management of patients. The addition of antibiotics, such as doxycycline, chloroquine, and immune boosters, has been recommended. There is an extreme variation in the incidence of mortality ranging from $2 \%$ to $12 \%$, according to reports from various countries across the globe. Oxygen therapy with various equipment which includes non-rebreathing masks and high-frequency nasal oxygen is commonly used for sick cases. The preferred use of non-invasive ventilation over intubation by a majority of intensivists is a significant therapeutic difference. Among the antivirals, oral favipiravir, parenteral remdesivir, and the newer upcoming molnupiravir are in the center stage.

\section{TRANSMISSION}

Current evidence about the transmission of COVID-19 suggests that the virus spreads by respiratory droplets among people who are in close contact with each other $<1 \mathrm{~m}$ apart. When a person sneezes or coughs, the virion output is much higher than when they speak. All these numbers correspond to unprotected contacts. It is now clear that the virions leave the infected person through coughing and sneezing. It is reasonable to believe that with elicited sneezing, the viral load will decrease. Chun et al. [3] have described the particles coming from turmeric smoke do possess anti-inflammatory and antiviral properties. The smoke by itself is a mild irritant to induce sneezing. Sneezing in the open air by inhaling turmeric smoke can decrease the viral load. All the evidence of practicing respiratory ethics of avoiding coughing and sneezing described in literature probably suits air conditioned closed spaces. Our opinion suggests expulsion of virus by induced sneezing will decrease the viral load, thereby decreasing the severity of the disease. The N95 mask is a useful adjunct to decrease transmission. However, the precision of wearing is not followed by many. The masks are usually worn a little loose to decrease fogging and the air leak from the side of the mask defeats the very purpose. Usually, the masks are pulled down to eat in hotels and restaurants. We feel a Partha's modified mask to prevent nasal entry could very well augur the purpose of decreased nasal transmission [4]. However, this concept of nasal masks to protect during feeding is not marketed. Innumerable modifications of masks are available on the market. It is better to have a 3 ply mask or and 
N95 to decrease transmission. The cloth masks are very tight and may not allow normal breathing. The N95 masks can be reused after $72 \mathrm{~h}$ of drying but we prefer to use them in camphor vapor with a possible unproven antiviral property [5]. It is our opinion to discourage the respirator mask as such because it depends on the integrity of the valve. If the valve malfunctions, the masks become ineffective.

\section{USE OF PERSONAL PROTECTIVE EQUIPMENT (PPE)}

The use of PPE has been promoted to be used by health workers to decrease the transmission of the virus. The severe acute respiratory syndrome (SARS) virus, after it gains entry through the skin of the health worker and his/her accidental touch on the face, is likely to give way to its destination in the nasopharynx. The regular and correct use of the equipment will decrease the transmission. There are a lot of inherent complications associated with its use. They are described below. Excessive sweating (100\%), fogging of goggles and/or face shields (88\%), suffocation (83\%), breathlessness (61\%), fatigue $(75 \%)$, headache when used for a longer time (28\%), and even a few pressure marks (19\%) are the described ones [6]. There is enough evidence to state that donning and doffing are not done properly by more than one-third of health workers [7]. This incorrect use may be associated with a failure of the PPE to protect. With its inherent complications and wrong use by a substantial percentage of people, a rising cost of health care, and an enormous increase in biomedical waste, the validity of its widespread use becomes questionable. During surgery, there is an overall but variable $223-769 \%$ risk of contamination from blood and body fluid splash on protective eye shields. A washable face shield provides answers to questions about the corona and biomedical waste. Even though the evidence promotes the use of PPE, our opinion questions the possibility of the virus entering the feet and ascending up to enter the nasopharynx. We promote for wearing face shields, N95 masks, gloves, a plastic gown, and socks. There is some concern about gloves touching the face. The gloves need to be sanitized regularly, but the biggest advantage is that the skin escapes from frequent alcohol exposure and its inherent skin issues for the health worker. There is a thin line between evidence and our opinion as we target the pathogenesis and suggest a protection technique to suit the needs of health workers of various countries.

\section{ANTIVIRAL DRUGS}

Remdesivir is an antiviral anti-COVID-19 drug that is given by intravenous infusion in the hospital. This drug can be given only to inpatients. However, there are criteria to make inpatients with RT-PCRpositive results. It looks illogical that outpatient corona patients need not be given remdesivir which questions the very efficacy of the drug. The admission criteria described are as follows:

1. Patients with dyspnea or respiratory rate $\geq 30$ breaths per min

2. Patients with oxygen saturation $\leq 94 \%$ on RA

3. Patients with sick comorbid conditions.

The second consideration is about lot of published studies which doubt the usefulness of remdesivir in corona patients. Solidarity trial initiated by the World Health Organization (WHO) [8] reiterates that there is no difference in morbidity or mortality with either the use or omission of remdesivir. We accept that it is the only US FDA approved antiviral drug for COVID patients. The other antivirals such as lopinavir, umifenovir, favipiravir, and oseltamivir have been used for these patients singly or in combination with variable results. Numerous studies also validate the usefulness of favipiravir which can be given orally as tablets and significantly at $10 \%$ of the cost of remdesivir [9]. In developing countries like India, a majority of patients land up for medical check-up after 3-4 days, after which they undergo RT-PCR testing. The results come the next day. If we calculate the days from symptoms, it will be nearly 6-7 days. In these days, the viral load is on the decreasing trend and to initiate remdesivir to continue till the $12^{\text {th }}$ day for 5 days sound different as there may not be any virions in majority of patients. If the patients are so health conscious to give the throat swab on day 1 to get the results in $12 \mathrm{~h}$ so that the initiation and completion of dosage of remdesivir is within 7 days, it may of be the described evidence-based use. It's a well-known fact that there are no clear-cut guidelines for primary contacts. The definition of primary and secondary contacts itself is intriguing. The contacts can be made to apply Mandl's paint in the throat and inside the nasopharynx as a swab by themselves 3-4 times a day which may be useful [5]. It's a simple logic that povidone-iodine is antiviral and its application as a paint which stays in the throat as a paint is going to kill the viruses at the time of their replication [10]. The paint has an additional glycerine which is anti-inflammatory and will decrease the symptoms of sore throat and loss of smell. It is our opinion to ensure widespread use of Mandl's paint to all the patients and contacts. We also suggest that any one going to a crowded place or hospital can apply this as a measure of prevention. Chloroquine and hydroxy chloroquine have demonstrable activities of stabilizing lysosomal membranes [11]. Hence, our opinion is to administer the drug in precise doses to selected individuals may be advantageous. There is a lot of recent evidence which discourages their use. Our opinion is if administered earlier, may decrease the severity of cytokine storm. There will not any changes in infectivity or incidence as they are not antiviral.

\section{MISCELLANEOUS}

Usually, the $1^{\text {st }}$ day of symptoms is to be considered the $1^{\text {st }}$ day of the timeline of the disease. The swab test for the throat is usually positive for the next 6-7 days. The described cytokine storm appears in the late $1^{\text {st }}$ week or the early $2^{\text {nd }}$ week. Its likely to get CT scan of the chest done in the $2^{\text {nd }}$ week is ideal [12]. Getting all the tests done on the same day as a package lacks scientific background. The chest findings are described due to endothelial inflammation and microthrombi. Thus, it is prudent to add steroids and anticoagulants in the $2^{\text {nd }}$ week rather earlier. All diabetics may need an additional insulin for 3-4 weeks for control as this disease may cause a metabolic breakdown to worsen diabetes mellitus. This is further aggravated by systemic steroids. A loss of smell indicates strongly the disease and early steroids retrieves smell in 3 days to 3 weeks. In our opinion, patients with loss of smell have less lung damage. A sudden fixed tachycardia in the early phase is a warning sign of impending hypoxemia in the $2^{\text {nd }}$ week [13]. We suggest to get the pulse oximeter to note the pulse in the $1^{\text {st }}$ week and saturation in the $2^{\text {nd }}$ week.

\section{PSYCHOLOGICAL PROBLEMS}

The COVID-19 pandemic has created unprecedented health and social challenges globally. The fear of death among people admitted even with mild illness is not addressed in many review articles. In our personal experience, we encounter patients writing death will on testament even with mild CT score in chest scans. People with known mental illnesses will be at uniquely high risk during this period. Compared with a global estimated prevalence of depression of $3.44 \%$ in 2017 , the prevalence of $25 \%$ depression appears to be 7 times higher, thus implicating COVID-19 outbreak on people's mental health [14]. The authors further reiterate that addressing this problem of mental health during and after this global health crisis should be placed into the international and national public health agenda as a top priority is necessary to improve citizens' well-being [15]. As soon as the COVID-19 spread across India, there were many hospitals involving emergency medicine pulmonary medicine, critical care professionals with a complete lack of understanding of the need of depressive illness. A very negligible percentage of health teams involved psychiatric counselors. Our opinion is to attach equal importance to psychiatrists and mental health counselors in the comprehensive team of corona warriors.

\section{NUTRITION}

A proper timed and healthy diet can guarantee a robust immune system. This can probably resist any onslaught by the virus. People who consume well-balanced diet appear to be safer protected against incidence of chronic diseases and infections [16]. Cintoni et al. [17] have stated that nutritional care both the health workers and the frail 
patients is inadequate in many hospital settings treating COVID cases. Suchitra and Parthasarathy [18] have described the essential nutrients targeting each property to counter the disease and planned a menu for each type of eaters. Such type of precise patient-based nutrition is not followed in many hospitals. Hence, our opinion is to promote this aspect of management which will supplement any type of pharmacological management.

\section{CONCLUSION}

There is a lot of published literature about the management of COVID-19 cases. Evidence is pouring for the use of antiviral drugs like remdesivir. The use of PPE kit was boasted as the sine qua non of decreased transmission. We found illogical that any entry of virus in the toe will reach nasopharynx and multiply. However, we promote the use of N95 masks, face shields, and gloves for hands. Our opinion encourages the use of povidone iodine as Mandl's paint in the throat to decrease the viral load. We also suggest to sneeze in open air with turmeric inhalation to attenuate the viral load. We put forward the theory on the early use of hydroxy chloroquine to cause membrane stabilization. This may decrease the intensity of cytokine storm in patients who are fit enough to take the drug. In all patients afflicted with COVID-19, we surmise that professional psychiatric counseling and nutritional support are neglected and need to be promoted.

\section{CONFLICTS OF INTEREST}

Nil for each author.

\section{FUNDING}

Nil.

\section{CONTRIBUTORSHIP}

Dr. SPS - writing, supervision and communication, concept in part, Dr. MS - ideas and concepts, Dr. AM - ideas and concepts.

\section{REFERENCES}

1. Bar-On YM, FlamholzA, Phillips R, Milo R. SARS-CoV-2 [COVID-19] by the numbers. eLife 2020;9:e57309.

2. Singhal T. A review of Coronavirus disease-2019 [COVID-19]. Indian J Pediatr 2020;87:281-6.

3. Chun S, Muthu M, Gansukh E, Thalappil P, Gopal J. The ethanopharmacological aspect of carbon nanodots in turmeric smoke. Sci Rep 2016;6:35586.
4. Parthasarathy S, Balachandar S. Partha's modified N 95 masks to assist feeding in COVID 19 patients. Int J Creat Res Thoughts 2020;8:1937-8.

5. Suchitra MR, Parthasarathy S. Partha's new techniques to counter corona virus-the usefulness of Camphor vapour and Mandl's paint. IJRPS 2020;11:472-4.

6. Agarwal A, Agarwal S, Motiani P. Difficulties encountered while using PPE kits and how to overcome them: An Indian perspective. Cureus 2020;12:e11652. Available from: https:/www.cureus.com/ articles/45409-difficulties-encountered-while-using-ppe-kits-andhow-to-overcome-them-an-indian-perspective. [Last accessed on 2021 Apr 07].

7. Verbeek JH, Rajamaki B, Ijaz S, Sauni R, Toomey E, Blackwood B, et al. Personal protective equipment for preventing highly infectious diseases due to exposure to contaminated body fluids in healthcare staff. Cochrane Database Syst Rev 2020;4:CD011621.

8. Stevanovikj M, Tacconelli E, Tikkinen KA, Trelle S, Zaid H, Røttingen JA, et al. Repurposed antiviral drugs for COVID-19-interim WHO solidarity trial results. N Engl J Med 2021;384:497-511.

9. Agrawal U, Raju R, Udwadia ZF. Favipiravir: A new and emerging antiviral option in COVID-19. Med J Armed Forces India 2020;76:370-6.

10. Naqvi SH, Citardi MJ, Cattano D, Ostrosky-Zeichner L, Knackstedt MI, Karni RJ. Povidone-iodine solution as SARS-CoV-2 prophylaxis for procedures of the upper aerodigestive tract a theoretical framework. J Otolaryngol Head Neck Surg 2020;49:77.

11. Browning DJ. Pharmacology of chloroquine and hydroxychloroquine. In: Hydroxychloroquine and Chloroquine Retinopathy. New York: Springer; 2014. p. 35-63. Available from: http://www.link.springer. com. [Last accessed on 2021 Apr 06]

12. Pan F, Ye T, Sun P, Gui S, Liang B, Li L, et al. Time course of lung changes at chest CT during recovery from Coronavirus disease 2019 (COVID-19). Radiology 2020;295:715-21.

13. Foster KJ, Jauregui E, Tajudeen B, Bishehsari F, Mahdavinia M. Smell loss is a prognostic factor for lower severity of Coronavirus disease 2019. Ann Allergy Asthma Immunol 2020;125:481-3.

14. Bueno-Notivol J, Gracia-García P, Olaya B, Lasheras I, López-Antón R, Santabárbara J. Prevalence of depression during the COVID-19 outbreak: A meta-analysis of community-based studies. Int $\mathrm{J}$ Clin Health Psychol 2021;21:100196.

15. Kontoangelos K, Economou M, Papageorgiou C. Mental health effects of COVID-19 pandemia: A review of clinical and psychological traits. Psychiatry Investig 2020;17:491-505.

16. Aman F, Masood S. How nutrition can help to fight against COVID-19 pandemic. Pak J Med Sci 2020;36:S121-3.

17. Cintoni M, Rinninella E, Annetta MG, Mele MC. Nutritional management in hospital setting during SARS-CoV-2 pandemic: A reallife experience. Eur J Clin Nutr 2020;74:846-7.

18. Suchitra MR, Parthasarathy S. Nutrition and corona virus: Plan a diet in a pandemic. IJRPS 2020;11:110-4. 